Editorial

ISSN: 2162-3104 Print/ ISSN: 2166-3750 Online

Volume 8, Issue 3 (2018), pp. 1267-1273

(C) Journal of International Students

http://jistudents.org/

doi:10.5281/zenodo. 1254578

\title{
Fostering Successful Integration and Engagement Between Domestic and International Students on College and University Campuses
}

\author{
CindyAnn Rose-Redwood \\ University of Victoria, Canada \\ Reuben Rose-Redwood \\ University of Victoria, Canada
}

\begin{abstract}
As the number of international students pursuing higher education abroad continues to increase globally (OECD, 2017), college and university campuses have the potential to serve as key spaces of cross-cultural learning and the cultivation of international friendships. Yet spatial proximity and intercultural contact do not always result in meaningful interactions between different social groups (Wessel, 2009). Various studies have shown that interactions between domestic and international students rarely result in cross-cultural friendships within higher educational settings (Trice, 2004; Gareis, 2012; Rose-Redwood \& Rose-Redwood, 2013). This disconnect between international students and host communities is often attributed to the failure of the former to "adjust" to the latter. However, as Ryan (2011) argues, international students are not simply "problems" in need of a solution by university administrators but rather "provide an opportunity for the co-construction of new knowledge and more collaborative ways of working and thinking" (p. 631 and 642). While much attention has been devoted to the challenges that international students face, there is also a need for scholars to consider innovative pathways toward building meaningful relationships between domestic and international students.

This special issue brings together a range of theoretical and empirical studies, as well as practitioner and personal narrative reflections, that advance our understanding of how best to foster successful integration and engagement between domestic and international students on college and university campuses. By shifting the focus from the problems of
\end{abstract}


"adjustment" to the possibilities of "mutual engagement," the contributions included in this special issue build upon the emerging body of literature on international student engagement (Glass, Wongtrirat, \& Buus, 2015; Kettle, 2017). In her recent book, International Student Engagement in Higher Education, Kettle (2017) calls for a student-centered approach to international student engagement that moves beyond the deficit model, which defines international students in terms of what they lack. While acknowledging the power imbalances within higher education settings, Kettle maintains that we must also consider the productive practices that enable international students to engage in meaningful and rewarding academic and social experiences when studying abroad. Glass, Wongtrirat, and Buus (2015) similarly call attention to the need for educational scholars to document "concrete examples of strategies to enhance the international student experience" (p. 3). Indeed, there is much to learn from such examples of successful strategies, programs, and practices that can help foster international student engagement, as the articles in the present issue of this journal illustrate.

In their contribution to this special issue, Glass and Gesing (this issue) present data indicating that participation in campus cultural organizations is correlated with the development of social networks that include students not only from one's own cultural background but also from a diverse range of cultures and nationalities. This leads them to suggest that campus organizations play an important role in fostering intercultural friendships that enhance international students' social capital and sense of belonging on campus. International student services (ISS) offices also help promote international student engagement through various outreach activities and programs, yet these services require effective communication strategies to inform international students of the opportunities for cross-cultural interaction. Ammigan and Laws' (this issue) study of international students' communication preferences demonstrates the usefulness of an "analyticsdriven communications strategy." Their results show that, despite the prevalence of social media, email and face-to-face interactions were the most preferred forms of communication among the international students who were surveyed. Moreover, international students from different countries may use a variety of social media channels, so it should not be assumed at the outset that Facebook is the most popular social media platform to communicate with international students. For instance, Ammigan and Laws (this issue) observe that We-Chat was the most widely 
used social media site among Chinese international students in their study; thus, a more targeted and holistic communications strategy will likely be more effective in reaching different segments of the international student body.

One strategy that ISS offices often adopt to encourage interactions between domestic and international students is the development of conversation partner programs. Aaron et al. (this issue) reflect upon their experiences as a team of faculty advisors and student leaders who designed and implemented a conversation partner program with minimal funding. Although challenges with such programs commonly arise, they argue that conversation partner programs can serve as "catalysts for the kind of interaction between domestic and international students that is at the basis for long-term friendship formation and networking" (Aaron et al., this issue). We agree that both domestic and international students have much to gain from developing such intercultural friendships. In our own contribution to this special issue (Rose-Redwood \& Rose-Redwood, this issue), we adopt a narrative-based approach to provide an in-depth discussion of two of our own long-lasting friendships with international students, one that developed from a conversation partner program and another that arose from a chance encounter in a campus cafeteria. In both cases, the development of meaningful intercultural friendships required "an active commitment on the part of both domestic and international students to engage in social interactions across the international divide" (Rose-Redwood \& RoseRedwood, this issue).

Institutional and individual efforts to build bridges across international divides on college and university campuses are central to the pursuit of mutual engagement between domestic and international students. However, Spitzman and Waugh (this issue) remind us that intercultural relations are "power-laden" interactions that are shaped not only by citizenship status but also by the politics of race, gender, and class, among other social differences. In response to a conversation partner program in which "students did not engage with one another on a deep level," Spitzman and Waugh (this issue) describe the development of a new workshop-based program called "Identity Dialogues" that challenges domestic and international student participants to confront their own stereotypes and prejudices over the course of seven weekly group conversation sessions. By addressing the politics of identity directly, programs such as Identity Dialogues provide students with the opportunity to openly discuss the power dynamics of intercultural engagement with the aim of working toward a more "empathetic understanding" of other cultures and perspectives. 
In addition to conversation partner programs and intercultural workshops, some academic units have gone a step further to incorporate international student engagement into the academic curriculum itself. Ranson's (this issue) account of an annual event known as "Mission Impossible," organized by the Gustavson School of Business at the University of Victoria, is a prime example. Recognizing that domestic students often avoid working with international students on group projects due to fear that this will negatively affect their class grades, Mission Impossible was designed to highlight the important contributions that international students can make to the co-production of knowledge. At the start of each academic year, incoming students compete in the Mission Impossible event with the goal of creating an environmentally sustainable business proposal. Students are divided into teams, each of which includes an international student together with domestic students, and the teams must develop a business plan for a company that could operate effectively within the international student's home country. This latter requirement positions the international student as the "expert" who has valuable knowledge to contribute to the group project, which changes "the power dynamic in the group [and] allows barriers to come down and students to get to know each other in a more respectful environment" (Ranson, this issue).

Another arena in which international student engagement can occur is the campus workplace. Su's (this issue) phenomenological study of Chinese undergraduate students supports the claim that on-campus employment offers important opportunities for interactions between international and domestic students as well as host national supervisors and staff. Interestingly, Su's (this issue) research finds that "financial reward was not the main motivation for the new generation of Chinese undergraduate students to engage in on-campus employment." Other motivations included improving English language skills, obtaining a social security number, gaining work experience, developing friendships with domestic students, and learning more about the culture of the host community. Su's (this issue) study highlights how the campus workplace environment can serve as a "supplementary educational space" for intercultural engagement.

Once educational scholars and practitioners move beyond deficitbased models of international students and develop initiatives and programs based upon the principles of mutual engagement, the possibilities for meaningful, intercultural interactions seem to multiply. Thomas et al. (this issue) discuss four "common grounds" that can serve as the basis for mutual engagement between domestic and international students, which include "common experience, cultural celebrations, faith, and common challenges." 
Drawing upon their own experiences at Simon Fraser University, Thomas et al. (this issue) illustrate how these principles have been put into practice through everything from community cooking workshops and holiday dinners to interfaith services and public demonstrations of solidarity with immigrants. Their reflections underscore how the university experience is about far more than academic studies alone since campus life also involves developing a sense of community.

Mitrayani and Peel (this issue) likewise call attention to the importance of intercultural community-building in their discussion of the East-West Center in Hawai ${ }^{6}$. As they explain, the East-West Center was established by the U.S. Congress in 1960 in order to "foster better relations and understanding" between the United States and Asia-Pacific countries. Students live in common dormitories and are expected to participate in extracurricular activities together in order to achieve the center's "mission of stimulating relationship building." As former students at the center, Mitrayani and Peel (this issue) consider the positive impact that it had on their shared experiences of collaborative, cross-cultural learning and how the program fosters a sense of "community where differences become an asset."

The general aims of the East-West Center are also reflected in the U.S. Fulbright program, which supports American students studying abroad as well as international students pursuing higher education in the United States. Metro-Roland (this issue) describes the strategies she has employed to facilitate international student engagement in her role as the Fulbright Foreign Student Advisor at Western Michigan University, an institution with one of the highest Fulbright enrollments nationally. She argues that a "rooted cosmopolitanism" can help create "communities organized around shared markers beyond national identity alone." In other words, a sense of belonging among both international and domestic students need not be defined solely through a nationalist frame but should rather be based upon "the multiplicity and fluidity of identity that these students bring into play" (Metro-Roland, this issue).

As university administrators laud the virtues of internationalization, Killick (this issue) contends that higher education institutions continue to understand international students largely through the lens of deficit modelling while few prioritize "the value of diverse student identities and perspectives." To address this issue, he proposes a series of guiding principles, goals, and outcomes of "critical intercultural practice." These include achieving academic success, developing intercultural competence, and cultivating a critical consciousness that questions the status quo of both local and global power relations. At a time when xenophobic ethno- 
nationalism is on the rise, however, critical pedagogies in the classroom and university-sponsored intercultural programs on campus may not be enough to ease the tensions between international students and the host community more generally. Consequently, Marangell, Arkoudis, and Baik (this issue) call for a community-based approach to international student integration that goes "beyond campus-specific policies" by engaging with the local community directly. Specifically, they recommend that colleges and universities develop community-based projects that connect international students with local community organizations, establish safeguards to prevent exploitation of international students by off-campus landlords and employers, and streamline information so that international students can make more informed decisions regarding their engagement with the host community.

If higher education institutions are serious about promoting internationalization, they have a responsibility to ensure that international students are treated fairly and are not exploited during their educational experiences. Waters (this issue) argues that scholars have not paid sufficient attention to the politics of international student mobilities, and she takes UK transnational education programs in Hong Kong as a case in point to underscore the political dimensions of exporting higher educational models abroad. As Waters (this issue) observes, those enrolled in transnational programs are transformed into "international students" within their very own countries, which results in them being perceived as internal "others" in comparison to domestic students in more traditional degree programs in Hong Kong. Moreover, such programs are often based upon a neocolonial model of knowledge transfer, yet at the same time students are not provided with the same benefits that domestic students receive at other local universities, and their "international" degrees are not afforded the same level of recognition within the social context of Hong Kong. Waters (this issue) suggests that, despite these problems, there is nevertheless potential for decolonizing the mandate of transnational education programs. However, this will require a commitment to rethink how the "global webs of responsibility" can be reconfigured in such a way that longstanding colonial hiearchies are challenged rather than reinforced.

Taken together, the contributions to this special issue examine the challenges and opportunities for international student engagement on college and university campuses in the twenty-first century. The strategies, programs, and practices that the various contributors discuss offer reason for 
hope that the goal of encouraging domestic and international students to meaningfully engage with each other in a spirit of mutuality is not some farfetched, utopian dream but is rather being put into practice through a series of concrete actions. Many of the challenges associated with intercultural engagement still remain, but there is clearly a lot of exciting work already being done, which will hopefully serve as inspiration for future educational scholars and practitioners to develop new innovative strategies that foster successful intercultural engagement between domestic and international students in the years ahead.

\section{REFERENCES}

Gareis, E. (2012). Intercultural friendships: Effects of home and host region. Journal of International and Intercultural Communication, 5(4), 309-328.

Glass, C., Wongtrirat, R., \& Buus, S. (2015). International student engagement: Strategies for creating inclusive, connected, and purposeful campus environments. Sterling, VA: Stylus Publishing.

Kettle, M. (2017). International student engagement in higher education: Transforming practices, pedagogies and participation. Bristol: Multicultural Matters.

OECD. (2017). Education at a glance 2017: OECD indicators. Paris: OECD Publishing. http://dx.doi.org/10.1787/eag-2017-en

Ryan, J. (2011). Teaching and learning for international students: Towards a transcultural approach. Teachers and Teaching, 17(6), 631-648.

Trice, A. (2004). Mixing it up: International graduate students' social interactions with American students. Journal of College Student Development, 45(6), 671-687.

Wessel, T. (2009). Does diversity in urban space enhance intergroup contact and tolerance? Geografiska Annaler: Series B, Human Geography, 91(1), 5-17.

CINDYANN ROSE-REDWOOD, $\mathrm{PhD}$, is an Assistant Teaching Professor in the Department of Geography at the University of Victoria. Her research examines the social experiences of international students in higher education settings, the social geographies of immigrant communities in North American cities, and the Caribbean diaspora. She is currently co-editing a book entitled, International Encounters: Higher Education and the International Student Experience (with Reuben Rose-Redwood). Email: cindyann@uvic.ca

REUBEN ROSE-REDWOOD, $\mathrm{PhD}$, is an Associate Professor in the Department of Geography at the University of Victoria. His research examines the cultural politics of place, critical social theory, and the spatialities of power. $\mathrm{He}$ is the editor of Performativity, Politics, and the Production of Social Space (2014, with Michael Glass), The Political Life of Urban Streetscapes: Naming, Politics, and Place (2018, with Derek Alderman and Maoz Azaryahu), and Gridded Worlds: An Urban Anthology (2018, with Liora Bigon). He is currently co-editing a book entitled, International Encounters: Higher Education and the International Student Experience (with CindyAnn RoseRedwood). Email: redwood@uvic.ca 